\title{
Residual Stresses in Explosively Welded Plates Made of Titanium Grade 12 and Steel with Interlayer
}

\author{
A. Karolczuk, H. Paul, Z. Szulc, K. Kluger, M. Najwer, and G. Kwiatkowski
}

\author{
(Submitted March 2, 2018; in revised form May 28, 2018; published online August 10, 2018)
}

\begin{abstract}
Distributions of residual stress components in explosively welded three-layer plate composed of titanium Grade 12, titanium Grade 1 and SA516 Grade 70 steel are investigated in this paper. The study applied the sectioning and the hole-drilling strain gage methods for residual stress measurement. The results have shown an inhomogeneous residual stress distribution, approximated by fourth-order polynomial along the thickness of a three-layer plate. Biaxial compressive residual stress state is observed in titanium Grade 12 and Grade 1 layers which change to tensile type in the vicinity of the interface between titanium Grade 1 and steel. Microstructure observation reveals the presence of the adiabatic shear bands in titanium Grade 12 layer at the interface with titanium Grade 1 interlayer. The observed distribution of residual stress components is justified by the occurrence of the shock wave phenomena.
\end{abstract}

Keywords residual stress, explosive welding, titanium Grade 12 multilayer material, adiabatic shear bands

\section{Introduction}

Materials with designed graded properties are very attractive for the industry since they are capable of offering a substitute to homogenous materials - thus providing improved performance of machines and structures (Ref 1-3). Specific engineering structures in nuclear and geothermal plants have to cope with high temperature and operate fault-free even under very corrosive environmental conditions (Ref 2, 4). In order to increase the reliability and decrease service cost, it is considered that some elements made of austenitic steels can be replaced by multilayer metallic materials with required properties (Ref 1). For example, titanium alloys offer excellent corrosive resistance, but have lower elasticity modulus compared to steel. The multilayer plate consisting of titanium alloy and steel layers could provide an adequate corrosion resistance, stiffness and endurance. Such plates could be obtained for example by explosive welding. The explosive welding technology was developed for industrial applications in the 1960 s and offers multilayer materials with required physical properties (Ref 5, 6). Higher fabrication costs are acceptable if the service life of industrial equipment containing multilayer material is increased. The explosive welding is unique technology since it applies energy of detonation to cause an impact of one material to another one during which a bond is created. The process of joining is difficult to investigate because of the high velocity of detonation wave (around $2000 \mathrm{~m} / \mathrm{s}$ ). This high velocity results in a very high rate of all processes taking place

A. Karolczuk, K. Kluger, M. Najwer, and G. Kwiatkowski, Faculty of Mechanical Engineering, Opole University of Technology, Mikołajczyka 5, 45-271 Opole, Poland; H. Paul, Institute of Metallurgy and Materials Science, Polish Academy of Sciences, Reymonta 25, 30-0 59 Kraków, Poland; and Z. Szulc, ZTW Explomet sp.j. Gałka, Szulc, Oświecimska 100, 46-020 Opole, Poland. Contact e-mail: a.karolczuk@po.opole.pl. during explosive welding such as plastic strain, phase transformation, heating and cooling.

Mechanisms leading to bond formation are still not fully understood. For the time being, explosion welding is defined as a solid-state welding process (Ref 6). However, recent studies have revealed that a thin diffusion layer (Ref 7-11) or even larger melted areas (Ref 11, 12) are formed between the materials that are bonded. Moreover, the melted areas could include intermetallic phases whose volumes are increased during post-welded heat treatment leading to a decrease in fatigue lifetime (Ref 12). The welded area also includes highly deformed grains and even micro-cracks as results of very rapid cooling rate (Ref 13, 14). Such welding inhomogeneities occupy a relatively small volume of materials comparing to the size of heat-affected zone created during traditional welding. As a result, the fatigue properties of multilayer materials could not differ significantly from mechanical properties of the parent materials (Ref 15). The very important issue from many points of view is associated with an existence of residual stresses in explosively welded elements. The residual stresses originate as a result of high deformation of joined materials locked in by a bond creation. If bonded materials have different thermal expansion properties, the performed heat treatment can only change the state of residual stresses, but cannot release them (Ref 16). It is well known that the residual stress has an influence on important properties of the materials. For example, tensile residual stress can induce corrosion cracking (Ref 17, 18), while the compressive stress can increase endurance and fatigue properties ( $\operatorname{Ref} 19,20)$. Additionally, the knowledge of residual stress distribution in explosively welded materials provides important insights regarding the process of explosive welding. In a recent paper ( $\operatorname{Ref} 16,21)$, it was demonstrated that tensile residual stress exists in the layer of titanium Grade 1 explosively welded to steel and the performed heat treatment changes the tensile state to the compressive one. Due to its high cold formability (elongation around 50\%), titanium Grade 1 is often used as a flyer layer (the layer accelerated by explosion). Features of the joining process such as lower stiffness (due to elasticity modulus and thickness) of flyer layer than stiffness of base plate made of steel and high cold formability of flyer layer 
enable one to create a simple model explaining the observed tensile residual stress in the titanium layer. During an explosion, the titanium layer is considerably compressed in one direction but elongated along the plane of impact - assuming no friction due to a thin melted zone. When the high pressure is released, the bond is already created and the previously induced elastic elongation is locked. As a result, the tensile residual stress is created. But in case of more than two welded layers with different physical properties, the above model could be invalid.

Sedighi and Honarpisheh (Ref 22) determined residual stress distribution in explosively welded $\mathrm{Al}-\mathrm{Cu}-\mathrm{Al}$ layers by using the incremental hole drilling method. It was found that the maximum value of the residual stress exists on the surface of the three-layer plate and the minimum compressive stress was identified in the $\mathrm{Cu}$ interlayer. The authors proposed a similar model as the one that was described above to explain such a distribution. However, the size of investigated samples and layers thickness is much smaller than studied in (Ref 16, 23).

Yasheng et al. (Ref 24) successively applied a milling technique to measure residual stresses in an explosively welded plate made of titanium, tantalum and steel layers. It was found that the highest tensile and compressive stresses occur at the interfaces and they are accompanied with the highest stress gradient. The tensile type of residual stress was found on the surface of the welded plate. The authors did not provide any explanation of the measured residual stresses.

Saksl et al. (Ref 25) applied micro-x-ray diffraction using synchrotron radiation to determine residual stresses in an explosively welded plate made of austenitic and pressure vessel steels. The applied technique gave the results of measurements of the principal residual strains at microscale in the vicinity of interface $( \pm 200 \mu \mathrm{m}$ from interface). It was found that the tensile type of maximum principal residual stress exists in the austenite phase (the flyer layer-austenitic steel), while minimum principal residual stress is compressive. In the base plate (pressure vessel steel), both principal stresses are compressive in the analyzed ferrite phase of steel.

Taran et al. (Ref 26) applied the neuron diffraction technique for residual stress measurement in an explosively welded cylindrical adaptor made of AISI 316L and titanium Grade 2. The compressive residual stresses were found in outer surface (steel), while tensile stresses occur in the inner surface (titanium).

In the present research, a three-layer plate composed of titanium Grade 12 and pressure vessel steel ASME SA516 Grade 70 with interlayer made of titanium Grade 1 is investigated. Titanium Grade 12 offers a better corrosion resistance and strength than titanium Grade 1 or titanium Grade 2 (Ref 27,28$)$, but its cold formability is low (i.e., elongation is no more than $20 \%$ ) and, as a result, it is necessary to apply an interlayer with a higher cold formability (Ti Grade 1) for the successful welding process.

The aim of the research reported in this paper is the determination of the residual stress distribution in the threelayer plate (Ti Grade 12/Ti Grade 1/Steel) obtained by the explosive welding process. Two methods of residual stress determination were applied: the sectioning method (Ref 29, 30) and the standard hole-drilling strain gage method (Ref 31 ).

\section{Experiment}

\subsection{Materials}

The multilayer plate consisting of three layers made of SA516 Grade 70 pressure vessel steel, titanium Grade 1 and titanium Grade 12 was obtained in an explosive welding process. Details concerning explosive welding parameters are confidential since unique combination of welded materials. The chemical composition and basic mechanical properties of the applied welded materials are presented in Tables 1, 2 and 3, where $E$ is the elastic modulus, $v$ is Poisson's ratio, $A$ is the elongation, $R_{p 02}$ is the yield strength, and $R_{m}$ is the tensile strength. The joining process was performed in two stages. In the first stage, a 3-mm-thick layer of titanium Grade 1 was cladded onto a 70-mm-thick plate of steel. In the second stage, titanium Grade 12 with a thickness of $9 \mathrm{~mm}$ was cladded onto the previously obtained bimetallic plate. The resulting threelayer plate and the intermediate bimetallic one were not subjected to any heat treatment. The dimensions of the final plate and location of an ignition point are shown in Fig. 1. The interlayer made of titanium Grade 1 is applied due to the low cold formability (elongation by around 20\%) of titanium Grade 12 , which cannot be directly welded to steel.

\subsection{Residual Stress Measurement}

The residual stresses were determined using two methods: The first one was based on the sectioning method (Ref 29, 30, 32 ), and the second one was the hole-drilling strain gage method (Ref 16, 31). For the application of the sectioning method, three samples $(\mathbf{A}, \mathbf{B}, \mathbf{C})$ were cut off from the threelayer plate. Detailed locations of four drilling spots P1, P2, P3, $\mathrm{P} 4$ and orientations of the cutout $\mathbf{A}, \mathbf{B}, \mathbf{C}$ samples are shown in Fig. 2. The location of the spots (P1, P2, P3, P4) was limited since only a small part (Fig. 2) of the welded plate was

Table 1 Chemical composition of SA516 Grade 70 steel (wt.\%)

\begin{tabular}{cccccccccccc}
\hline $\mathbf{C}$ & $\mathbf{M n}$ & $\mathbf{S i}$ & $\mathbf{P}$ & $\mathbf{S}$ & $\mathbf{C r}$ & $\mathbf{N i}$ & $\mathbf{C u}$ & $\mathbf{A l}$ & $\mathbf{N b}$ & $\mathbf{T i}$ & $\mathbf{F e}$ \\
\hline 0.17 & 1.43 & 0.37 & 0.015 & 0.003 & 0.03 & 0.03 & 0.04 & 0.035 & 0.019 & 0.006 & Balance \\
\hline
\end{tabular}

Table 2 Chemical composition of titanium Grade 1 and Grade 12 (wt.\%)

\begin{tabular}{|c|c|c|c|c|c|c|c|c|c|}
\hline Titanium & $\mathbf{N}$ & $\mathrm{C}$ & $\mathbf{H}$ & $\mathrm{Fe}$ & O & $\mathbf{N i}$ & Mo & Residuals & $\mathbf{T i}$ \\
\hline Grade 1 & 0.005 & 0.006 & 0.003 & 0.044 & 0.045 & $\ldots$ & $\ldots$ & $<0.25$ & Balance \\
\hline Grade 12 & 0.006 & 0.012 & 0.0012 & 0.06 & 0.160 & 0.600 & 0.270 & $<0.40$ & Balance \\
\hline
\end{tabular}


Table 3 Basic mechanical properties of parent materials

\begin{tabular}{llllll}
\hline Material & $\boldsymbol{E}, \mathbf{G P a}$ & $\boldsymbol{v},-$ & $\boldsymbol{A}, \boldsymbol{\%}$ & $\boldsymbol{R}_{\boldsymbol{p 0 2}}, \mathbf{M P a}$ & 361 \\
\hline SA516 Grade 70 & 200 & 0.30 & 26.8 & $\boldsymbol{R}_{\boldsymbol{m}}, \mathbf{M P a}$ \\
Titanium Grade 1 & $100-105$ & $0.28-0.39$ & $41-52$ & $176-226$ & 529 \\
Titanium Grade 12 & $100-105$ & $0.28-0.39$ & $18-20$ & $405-530$ & $600-650$ \\
\hline
\end{tabular}

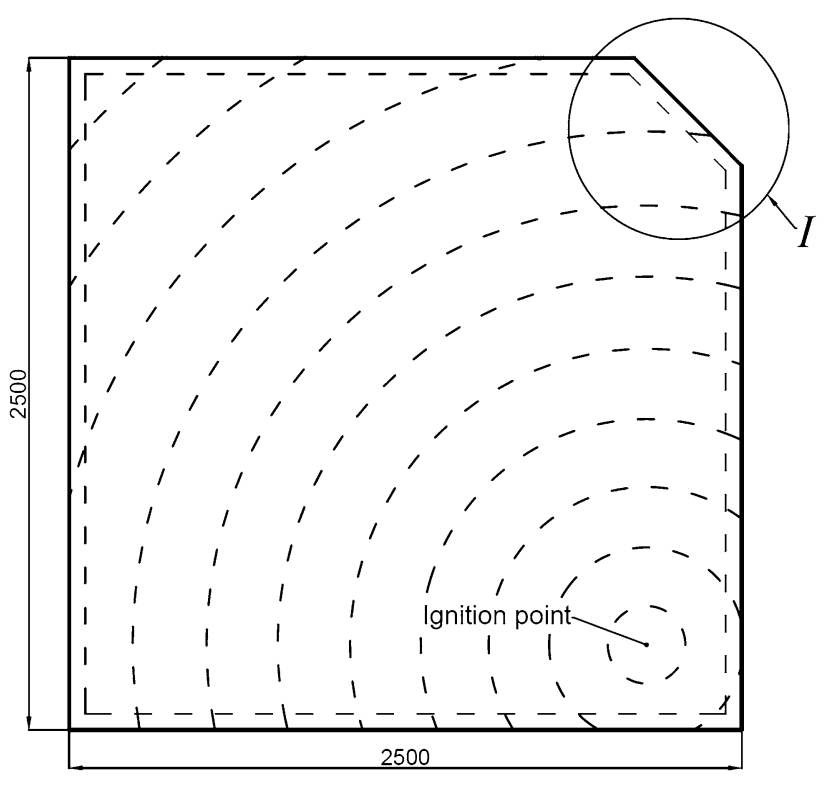

Fig. 1 Plate dimensions, locations of ignition point and investigated area (detail $I)$

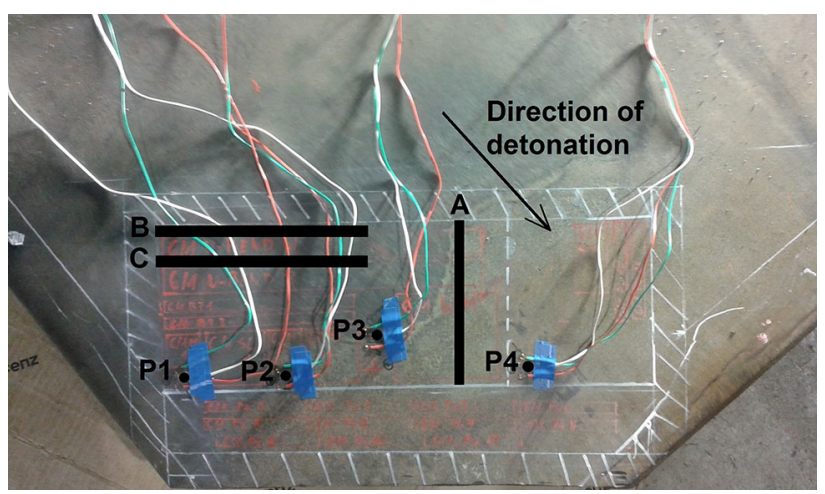

Fig. 2 Detail $I$ (rotated clockwise by $135^{\circ}$ from the position presented in Fig. 1) with marked locations of the A, B, C samples and spots P1, P2, P3, P4 with drilled holes

allocated to mechanical tests. Thus, the selected spots were located in the available space between the areas reserved for test samples. Both methods are based on the calculation of residual stresses expressed by means of strain relieved due to the drilled hole or cutting out selected parts of the material. Different orientation of the $\mathbf{A}$ and $\mathbf{B}$ samples allows calculating two components of the residual stress state. Unlike samples A and $\mathbf{B}$, sample $\mathbf{C}$ was subjected to the heat treatment in order to investigate its influence on the distribution of the relieved strain. The heat treatment consists of heating the $\mathbf{C}$ sample for $90 \mathrm{~min}$ at $610^{\circ} \mathrm{C}$ and then cooling in a furnace to $300{ }^{\circ} \mathrm{C}$ at velocity $100^{\circ} \mathrm{C} / \mathrm{h}$. The final cooling stage was carried out outside the furnace. Each of the $\mathbf{A}, \mathbf{B}, \mathbf{C}$ samples contains three layers with full thickness $(70+3+9 \mathrm{~mm})$.

\subsection{The Sectioning Method}

The procedure of applied sectioning method for residual stress determination involved several steps: (1) measurement of relieved deformation due to slicing of thin sheets of materials from the A, B, C samples; (2) calculation of relieved strain components; (3) calculation of the residual stress components.

Step (i). Seven thin sheets were sliced from the A, B, C samples (Fig. 3 and 4) using a water jet to reduce the generated heat. The sheets were sliced starting from the surface of titanium Grade 12. Due to the relaxation of residual stresses, the slices are deformed. Deformation of cut out slices was determined by measurement of change in length $\Delta L$ and deflection $f$ (Fig. 3). Initially, a caliper rule was used to measure the deflection $f$ and then the slice was straightened to determine the length change $\Delta L$. The results of measurements are presented in Table 4.

Step (ii). The distribution of relieved axial strain is not uniform across the slice section, but it can be decomposed into uniform and non-uniform parts. The uniform part is represented by the measured length change $\Delta L$ as follows:

$\varepsilon^{\mathrm{uni}}=\frac{\Delta L}{L}$.

The non-uniform part is represented by the measured deflection $f$. Since only deflection $f$ was measured, some assumptions need to be made during the calculation of the nonuniform strain distribution. It is assumed that the non-uniform distribution along $z$-direction of relieved axial strain does not change along $x$ and $y$ dimensions. This assumption along with the linear elastic beam theory and the small strain regime lead to the following expression for maximum value of non-uniform part of the axial strain:

$\varepsilon^{\text {non }}=\frac{2 \cdot f \cdot h}{L^{2}}$.

Finally, the total extremes values of axial strain on the outer surfaces of the slices are expressed as follows:

$\varepsilon=\frac{\Delta L}{L} \pm \frac{2 \cdot f \cdot h}{L^{2}}$

Three values of the relieved axial strain were obtained for each of the slices: one in the middle of the sheet, i.e., $\varepsilon=\Delta L / L$ and two on the outer surfaces, based on Eq 3. The obtained discrete values of relieved axial strain were approximated by a fourth-order polynomial in order to obtain a continuous function of strain distribution along $z$-direction. The continuous function of strain distribution is necessary for the calculation of residual stress. The discrete and continuous distributions of the relieved axial strain are presented in Fig. 5 for the $\mathbf{A}, \mathbf{B}, \mathbf{C}$ samples. Additionally, the confidential intervals containing $50 \%$ of the predictions of future observations are also 


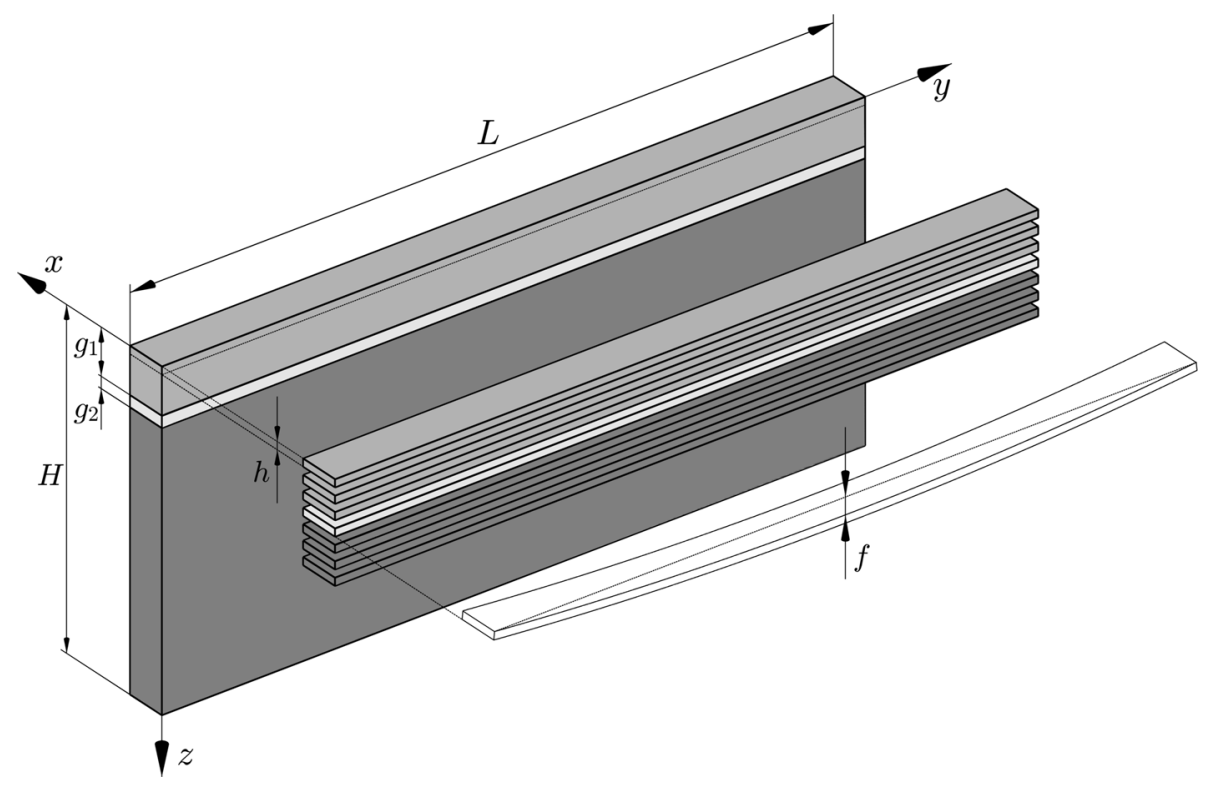

Fig. 3 Scheme of the sample and cut out slices with $x y z$ coordinate system assigned to the $\mathbf{B}$ sample $\left(g_{1}=9 \mathrm{~mm}, g_{2}=3 \mathrm{~mm}, H=82 \mathrm{~mm}\right)$

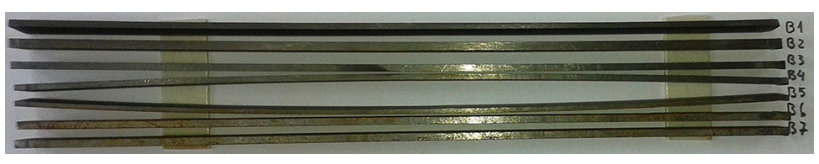

Fig. 4 Photograph of seven sheets sliced from the $\mathbf{B}$ sample

calculated and presented in Fig. 5. Discrete values are presented with error bars calculated using a total differential of function (3), assuming that error throughout all measurements is equal to $0.05 \mathrm{~mm}$.

Step (iii). Distribution of residual stress components $\sigma_{x}^{r}(z)$ and $\sigma_{y}^{r}(z)$ is calculated on the basis of the formerly determined distribution of the relieved axial strains. It is assumed that the relieved axial strain in the $\mathbf{A}$ and $\mathbf{B}$ samples represents $\varepsilon_{x}^{r}$ and $\varepsilon_{y}^{r}$ components of the relieved strain state. Applying the linear elastic material model and assuming the plane stress state $\sigma_{z}^{r}(z)=0$, the following expressions for the residual stress components are derived:

$\sigma_{x}^{r}(z)=-\frac{E(z)\left[\varepsilon_{x}^{r}(z)+v(z) \varepsilon_{y}^{r}(z)\right]}{1-v(z)^{2}}$,

$\sigma_{y}^{r}(z)=-\frac{E(z)\left[\varepsilon_{y}^{r}(z)+v(z) \varepsilon_{x}^{r}(z)\right]}{1-v(z)^{2}}$,

where

$$
\begin{aligned}
& E(z)=\left\{\begin{array}{ccc}
105 \mathrm{GPa} & \text { for } & 0 \leq z \leq 15 \mathrm{~mm} \\
200 \mathrm{GPa} & \text { for } & z>15 \mathrm{~mm}
\end{array},\right. \\
& v(z)=\left\{\begin{array}{ccc}
0.34 & \text { for } & 0 \leq z \leq 15 \mathrm{~mm} \\
0.30 & \text { for } & z>15 \mathrm{~mm}
\end{array} .\right.
\end{aligned}
$$

The calculated distributions of the residual stress components along with confidential intervals are presented in Fig. 6.
2.3.1 The Hole-Drilling Strain Gage Method. The holedrilling strain gage method is a standard method described in Ref 31. It involves an incremental hole drilling in the center of special strain gage rosette. In each step of drilling, the strain change around the drilled hole is measured and it is considered as an indicator of the relaxed stress. In the present research, four spots for drilling were selected (Fig. 2). The applied threeelement strain gage rosette (produced by TML Tokyo Sokki Kenkyujo Co., Ltd.) belongs to type A according to ASTM (Ref 31) with the following features: gage length $1.5 \mathrm{~mm}$, width $1.3 \mathrm{~mm}$, outer diameter $9.5 \mathrm{~mm}$, centerline diameter $5.14 \mathrm{~mm}$, nominal resistance $120 \pm 0.5 \Omega$ and gage factor 2.0. The depth of each drilling step was equal to $0.2 \mathrm{~mm}$ up to the final depth equal to $2 \mathrm{~mm}$. After each step, the strains in three directions were measured after signals have stabilized. The holes were drilled with Proxxon BFW 40/E driller using a rotational speed equal to $6000 \mathrm{rpm}$ using a face milling cutter with a diameter equal to $2 \mathrm{~mm}$. Using the calculation procedure described in Ref 31, the residual principal stresses $\sigma_{1}, \sigma_{2}$ and angle $\beta$ (clockwise) between directions of the maximum principal stress $\sigma_{1}$ and detonation velocity were calculated. The results are presented in Table 5 .

\subsection{Microstructure}

Selected micrographs of subsequent slices (B1, B3, B4 and B6) are presented in Fig. 7. The observed plane of micrographs coincides with the $y z$ plane presented in Fig. 3. The microstructure of titanium Grade 12 (B1 and B3 slices) does not change significantly along the plate thickness up to the vicinity of the interface with titanium Grade 1. The perceptible anisotropy of titanium Grade 12 microstructure results from the cold rolling process. The micrograph of slice B4 represents equiaxed (along the whole thickness) grains of $\alpha$ phase in titanium Grade 1. Slice B6 made of SA516 Grade 70 steel has typical ferrite-pearlite microstructure. A comparison of microstructures between slices cut out from the B sample without the heat treatment and the $\mathbf{C}$ sample after the heat 
Table 4 Initial lengths $L$ of the A, B, C samples, thickness $h$, elongation $\Delta L$, deflection $f$ and elasticity modulus $E$ of the cut out slices

\begin{tabular}{|c|c|c|c|c|c|c|c|c|}
\hline$L=187.00 \mathrm{~mm}$ & $h, \mathrm{~mm}$ & 3.24 & 1.87 & 1.62 & 1.51 & 2.13 & 2.26 & 2.23 \\
\hline \multirow[t]{3}{*}{ A } & $f, \mathrm{~mm}$ & 0.39 & 0.79 & 0.61 & 2.22 & 0.17 & 0.07 & 0.19 \\
\hline & $\Delta L, \mathrm{~mm}$ & 0.15 & 0.25 & 0.15 & 0.05 & -0.1 & -0.15 & -0.15 \\
\hline & $E, \mathrm{GPa}$ & 105 & 105 & 105 & 105 & 200 & 200 & 200 \\
\hline$L=187.40 \mathrm{~mm}$ & $h, \mathrm{~mm}$ & 1.64 & 2.16 & 1.72 & 1.44 & 1.25 & 1.82 & 1.91 \\
\hline \multirow[t]{3}{*}{ B } & $f, \mathrm{~mm}$ & 0.66 & 0.72 & 0.80 & -1.87 & 2.84 & 0.00 & 0.01 \\
\hline & $\Delta L, \mathrm{~mm}$ & 0.15 & 0.25 & 0.30 & 0.15 & 0.15 & -0.05 & -0.1 \\
\hline & $E, \mathrm{GPa}$ & 105 & 105 & 105 & 105 & 105 & 200 & 200 \\
\hline$L=187.14 \mathrm{~mm}$ & $h, \mathrm{~mm}$ & 1.91 & 1.92 & 1.84 & 1.18 & 1.55 & 1.96 & 1.77 \\
\hline \multirow[t]{3}{*}{$\mathrm{C}$} & $f, \mathrm{~mm}$ & 0.46 & 0.84 & 0.84 & -0.84 & 0.64 & 0.01 & 0.10 \\
\hline & $\Delta L, \mathrm{~mm}$ & 0.26 & 0.36 & 0.31 & 0.11 & 0.06 & -0.24 & -0.19 \\
\hline & $E, \mathrm{GPa}$ & 105 & 105 & 105 & 105 & 105 & 200 & 200 \\
\hline
\end{tabular}
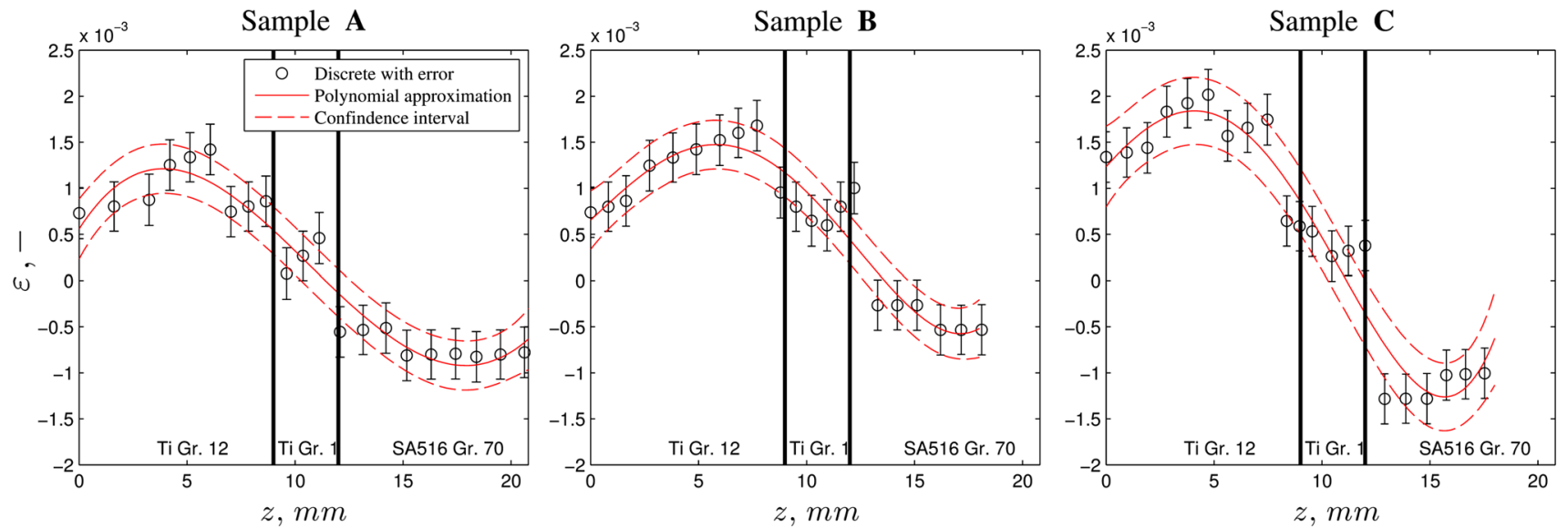

Fig. 5 Relieved axial strain distributions in the A, B, C samples along $z$-direction through all welded layers
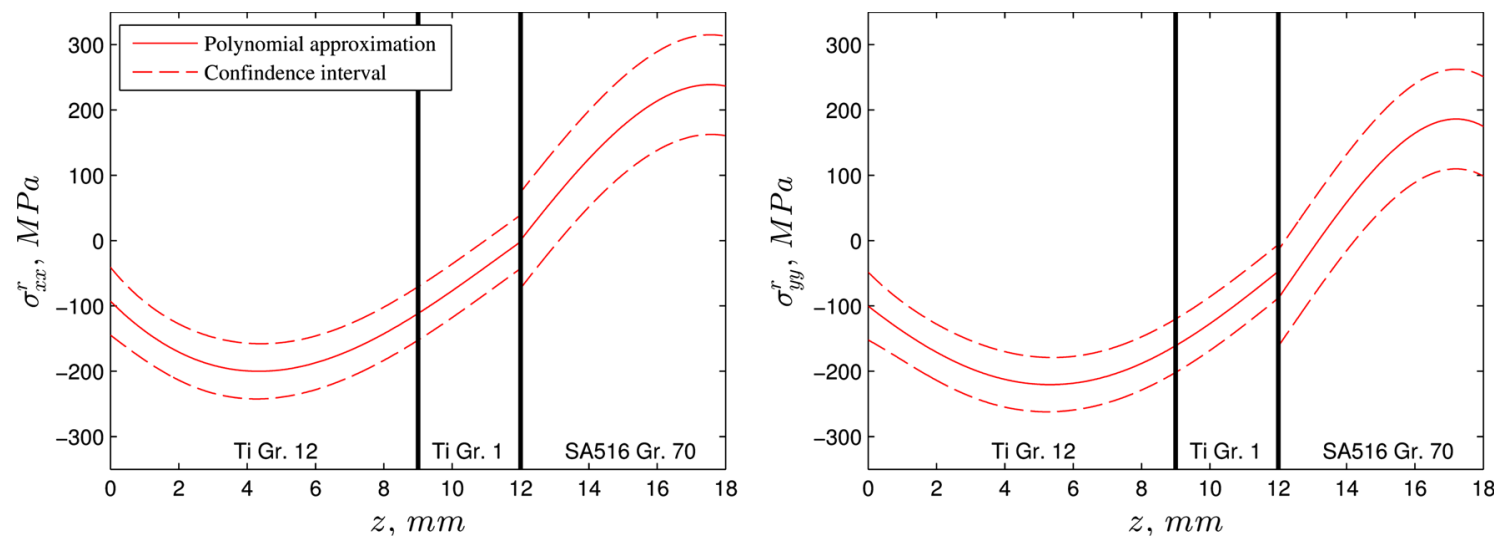

Fig. 6 Distribution of the residual stress components

Table 5 Residual stresses in titanium Grade 12 determined according to the hole-drilling strain gage method

\begin{tabular}{|c|c|c|c|c|c|c|c|c|c|c|c|}
\hline \multicolumn{3}{|l|}{ P1 } & \multicolumn{3}{|c|}{ P2 } & \multicolumn{3}{|c|}{ P3 } & \multicolumn{3}{|c|}{ P4 } \\
\hline$\sigma_{1}, \mathrm{MPa}$ & $\sigma_{2}, \mathbf{M P a}$ & $\beta,^{\circ}$ & $\sigma_{1}, \mathrm{MPa}$ & $\sigma_{2}, \mathrm{MPa}$ & $\beta,^{\circ}$ & $\sigma_{1}, \mathrm{MPa}$ & $\sigma_{2}, \mathrm{MPa}$ & $\beta,{ }^{\circ}$ & $\sigma_{1}, \mathrm{MPa}$ & $\sigma_{2}, \mathrm{MPa}$ & $\beta,^{o}$ \\
\hline-252 & -326 & -56 & -281 & -334 & -58 & -269 & -392 & -148 & -309 & -366 & -111 \\
\hline
\end{tabular}

treatment reveals that there are no significant differences. Apparently, the typical heat treatment with temperature $610^{\circ} \mathrm{C}$ designated to recrystallize the strongly deformed titanium grains in the vicinity of the interface is too low to significantly change the microstructure of titanium Grade 12 and equiaxed grains of titanium Grade 1. The micrographs 

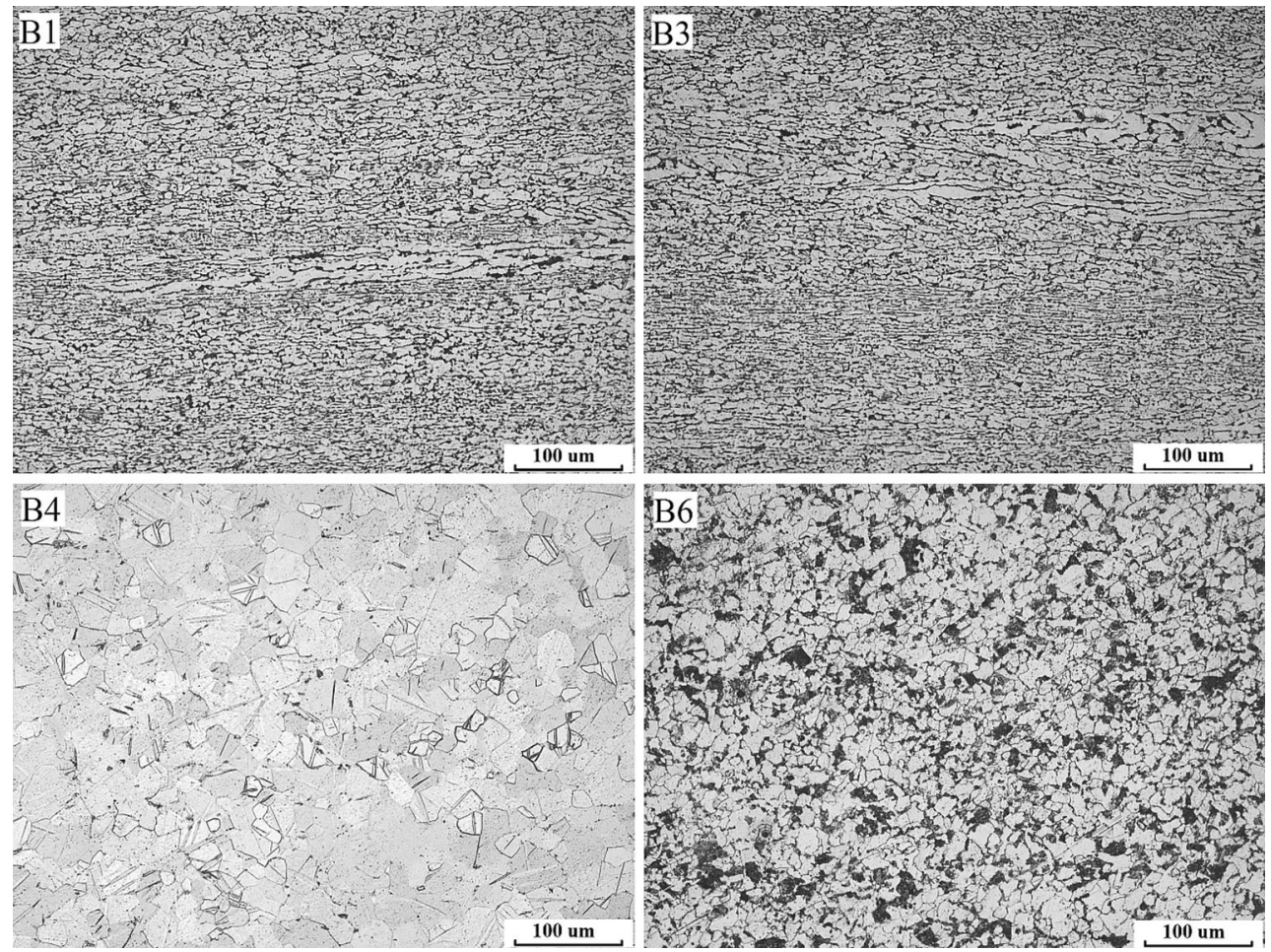

Fig. 7 Micrographs $(\times 200)$ of the following slices: B1 (Ti Grade 12), B3 (Ti Grade 12), B4 (Ti Grade 1) and B6 (SA516 Grade 70 steel)
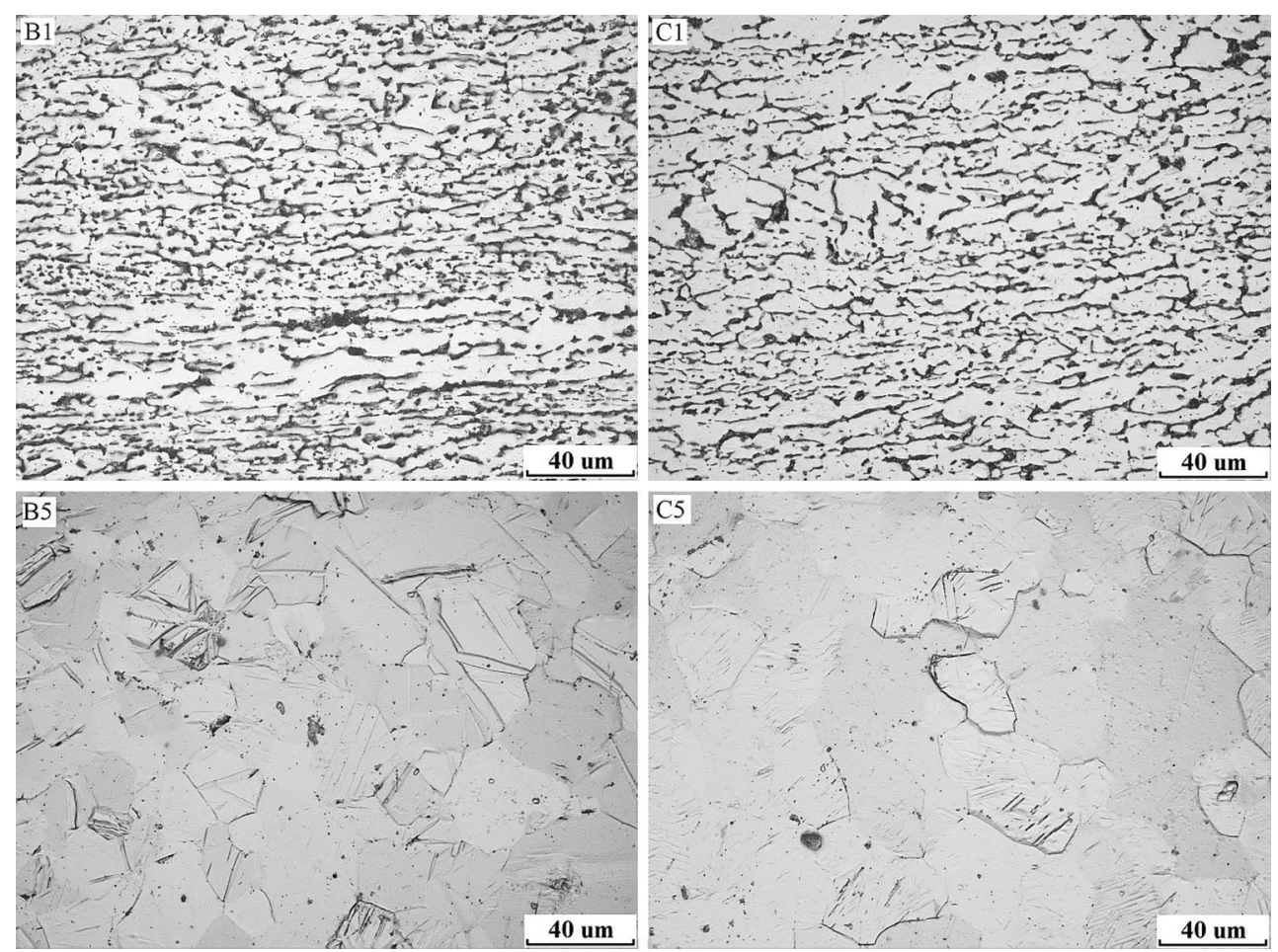

Fig. 8 Micrographs $(\times 500)$ of the following slices: B1 (Ti Grade 12), C1 (Ti Grade 12), B5 (Ti Grade 1) and C5 (Ti Grade 1)

presented in Fig. 8 do not reveal evident boundaries of grains in titanium Grade 12.

The microstructure (on the $y z$ plane, Fig. 3) at the interfaces between Ti Grade 12/Ti Grade 1 and Ti Grade 1/SA516 Grade 70 steel is presented in Fig. 9. The observed interface Ti Grade $12 /$ Ti Grade 1 has an irregular character in contrary to the characteristic wavy form of the titanium-steel interface. The microstructure of titanium Grade 12 in the zone up to around $200 \mu \mathrm{m}$ from the interface is largely deformed. Characteristic anisotropic microstructure being the result of the cold rolling process is rotated by around $21^{\circ}$ (Fig. 10) at the distance around $100 \mu \mathrm{m}$ from the interface, and the rotation angle 

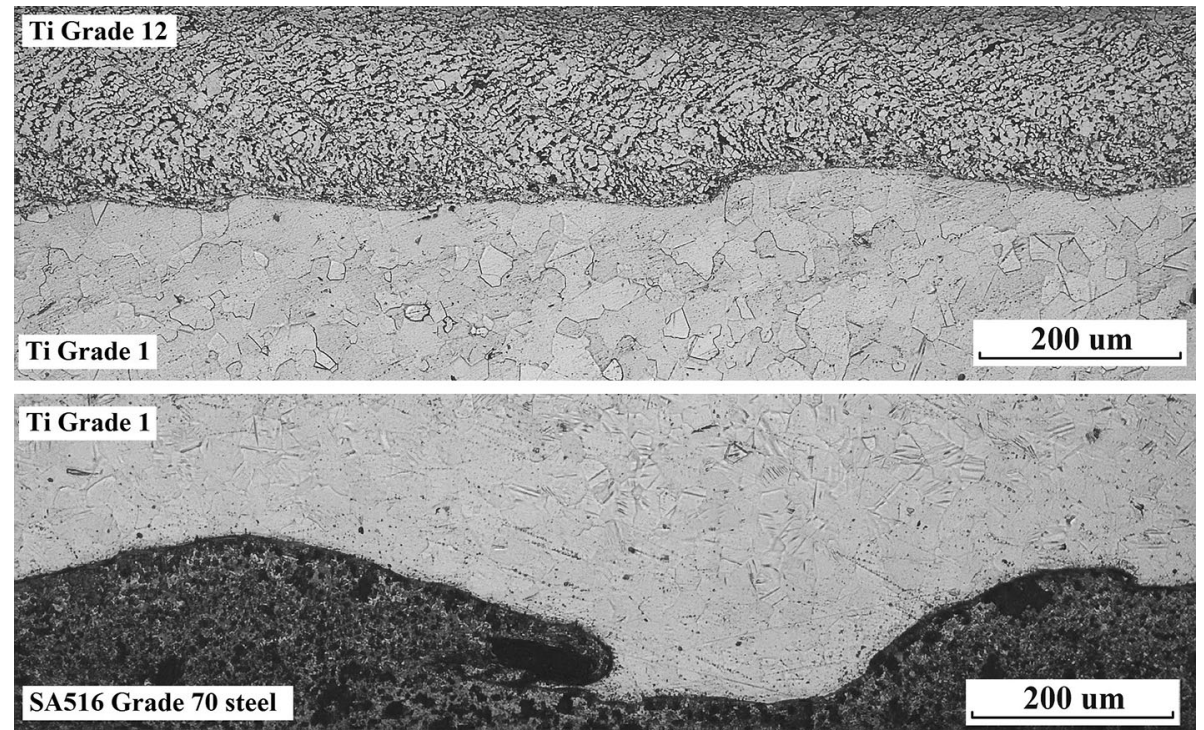

Fig. 9 Micrographs of the interface zone between Ti Grade 12/Ti Grade 1 and SA516 Grade 70 steel
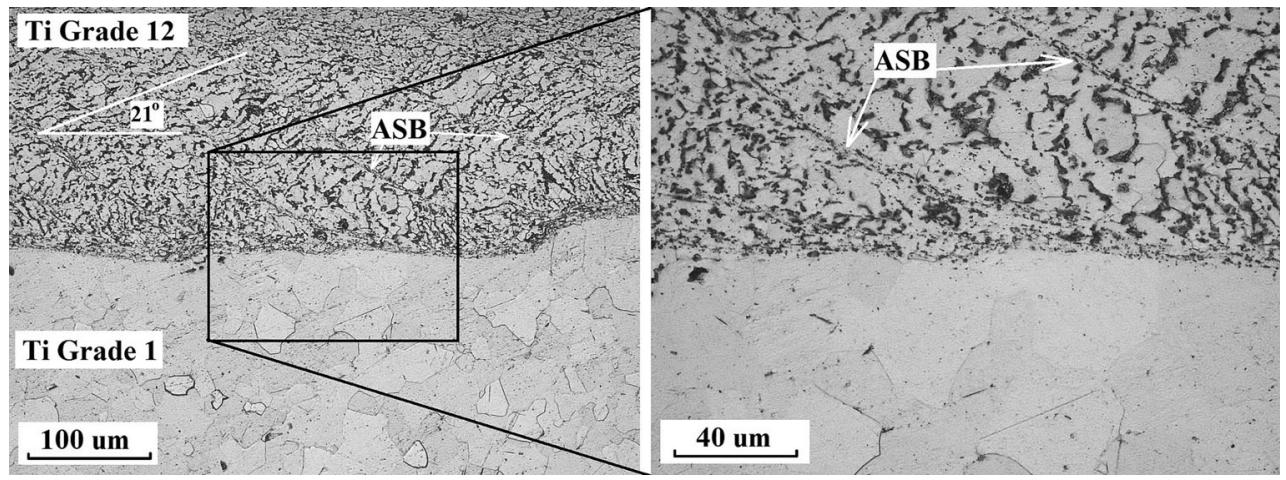

Fig. 10 Micrographs of the interface zone between titanium Grade 12 and Grade 1 with visible adiabatic shear bands (ASB) at different magnifications

increases almost to $90^{\circ}$ at the interface. Such a considerable deformation is partly possible due to forming of the adiabatic shear bands (ASB, Fig. 10). The adiabatic shear bands are characteristic for largely deformed microstructures at high rates in which heat transfer is limited. They are often observed in titanium alloys subjected to explosive welding (Ref 12, 33-36) or other dynamic processes (Ref 37,38$)$.

Transmission electron microscopy (TEM) observation reveals the presence of equiaxed and acicular grains (Fig. 11) in a sample of titanium Grade 12 taken from the vicinity of the plate surface. The observed equiaxed grains are around $2 \mu \mathrm{m}$ in size, and the acicular grains have a width of around $0.2 \mu \mathrm{m}$. The TEM observation of titanium Grade 12 in the vicinity of interface (Fig. 12) exhibits an irregular and elongated microstructure with refined grains around $0.4 \mu \mathrm{m}$ in size.

Microstructure observations of titanium Grade 12 sample (the vicinity of plate surface) using the high-angle annular darkfield (HAADF) scanning/transmission detector combined with an energy-dispersive X-ray (EDX) microanalyzer reveal (Fig. 13) concentrations of $\mathrm{Ni}$ and Mo elements at the grain boundaries. The results are supported by a point EDX analysis. The chemical composition can be referred to the presence of $\mathrm{Ti}_{2} \mathrm{Ni}$ and $\mathrm{Ti}_{2} \mathrm{Mo}$ phases at the grain boundaries (Ref 39).

\section{Analysis of Results}

The distribution of the relieved axial strain obtained by the sectioning method reveals a similar tendency in all $\mathbf{A}, \mathbf{B}, \mathbf{C}$ samples (Fig. 5). The highest positive strain values are recorded in the middle of the titanium Grade 12 layer. From this location, the strains decrease along thickness-crossing zero value in the titanium Grade 1 layer and reaching a minimum negative value at around $16-17 \mathrm{~mm}$ from the plate surface. Samples A and B with perpendicular symmetry axes and not subjected to the heat treatment demonstrate an almost identical relieved strain distribution, $\varepsilon_{x}^{r} \approx \varepsilon_{y}^{r}$. The relieved strain distribution in the $\mathbf{C}$ sample subjected to the heat treatment is characterized by more extreme values. The strain range in the $\mathbf{C}$ sample is equal to 0.0031 , while in the $\mathbf{A}$ and B samples is equal to 0.002 .

The relieved strain distributions approximated to fourthorder polynomial functions in the $\mathbf{A}$ and $\mathbf{B}$ samples offer the calculation of the distribution of residual stress components $\sigma_{x}^{r}(z)$ and $\sigma_{y}^{r}(z)$. We can observe that residual stress relaxed by deflection $f$ of the sheet is several times lower than residual stress relaxed by extension $\Delta L$. The negative values of $\sigma_{x}^{r}(z)$ 

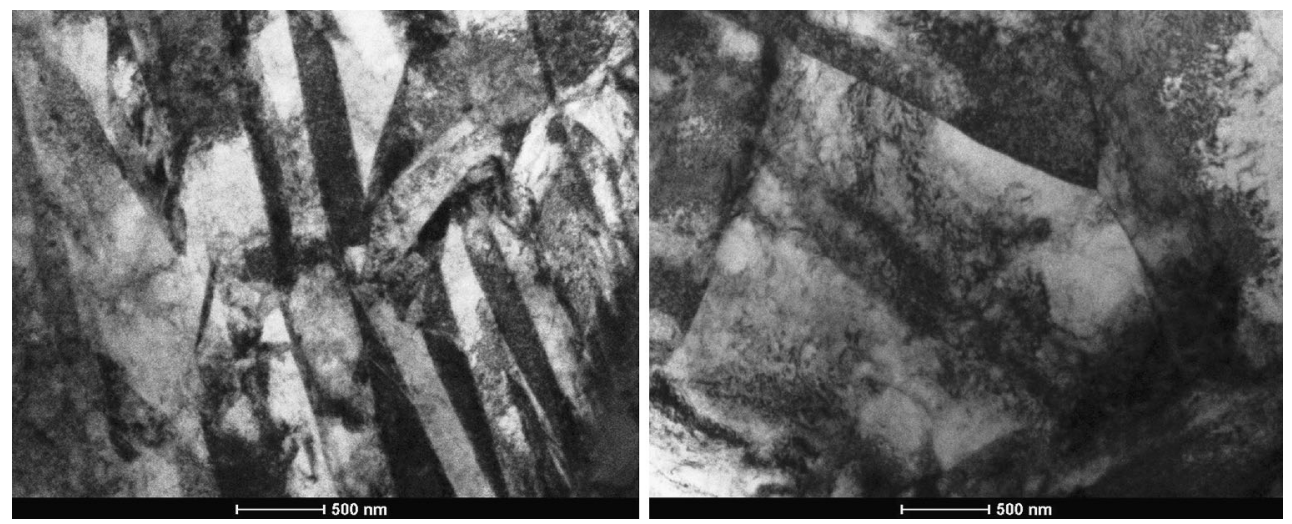

Fig. 11 Bright-field TEM images showing the representative microstructures of titanium Grade 12 taken from the area in the vicinity of plate surface
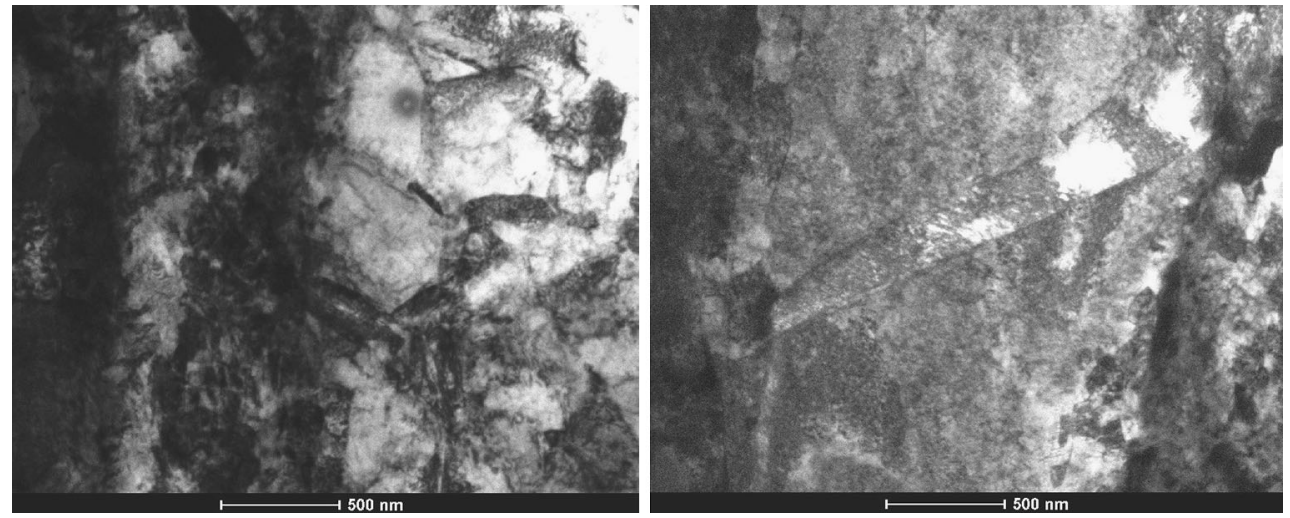

Fig. 12 Bright-field TEM images showing the representative microstructures of titanium Grade 12 taken from the area in the vicinity of an interface with titanium Grade 1
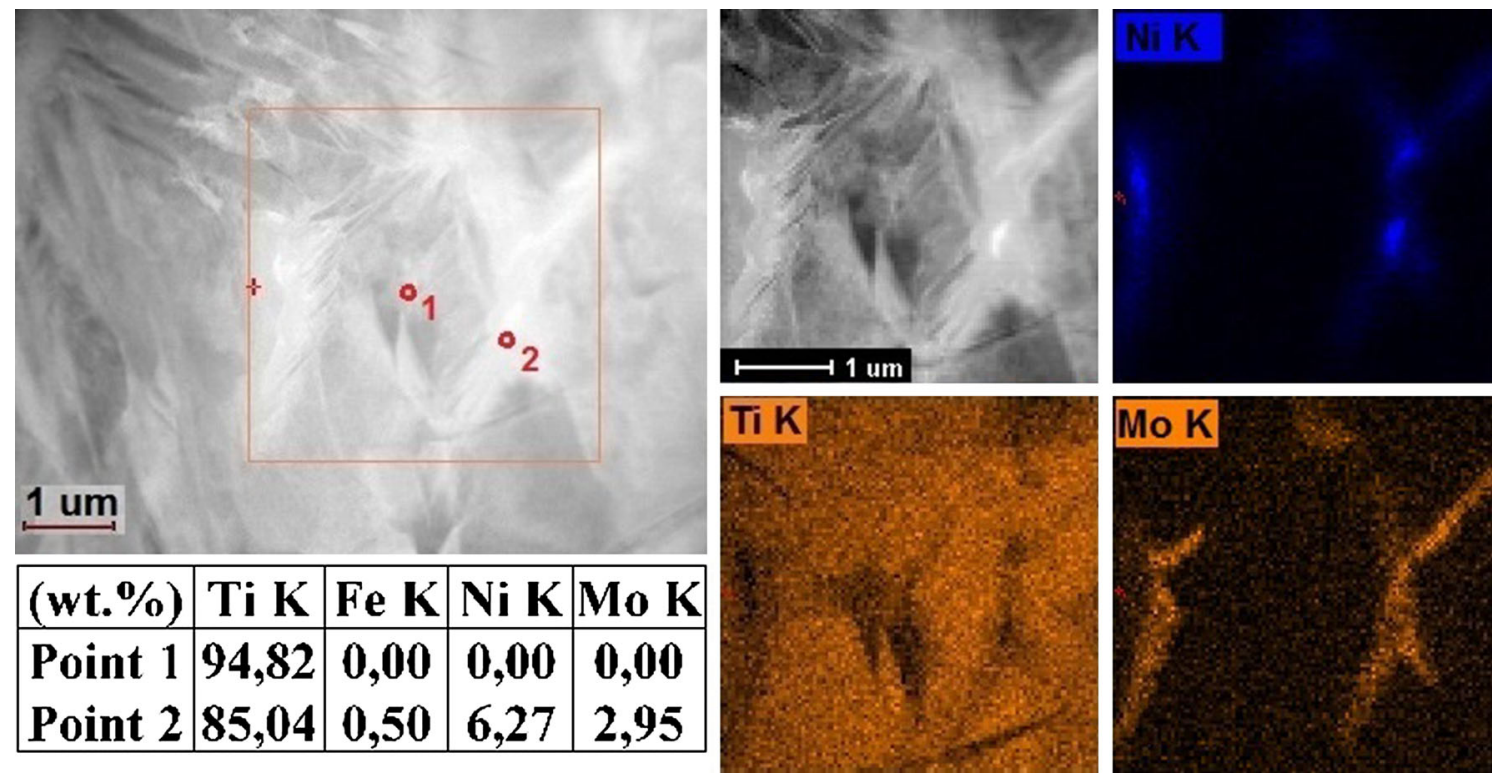

Fig. 13 HAADF image of titanium Grade 12 in the vicinity of free surface with EDX analysis

and $\sigma_{y}^{r}(z)$ occur on the plate surface and achieve minimum in the middle layer of titanium Grade 12. Approaching the interface with titanium Grade 1 , the values of $\sigma_{x}^{r}(z)$ and $\sigma_{y}^{r}(z)$ grow, but still remain negative in the middle of titanium Grade 1 layer. Zero values are obtained very close to the second interface at the depth around 11-13 $\mathrm{mm}$ from the plate surface. 
In general, the positive values of $\sigma_{x}^{r}(z)$ and $\sigma_{y}^{r}(z)$ occur in the steel layer.

The principal residual stresses determined by the holedrilling strain gage method in all four points give negative values in the range [-392, -252] $\mathrm{MPa}$. These values represent averaged residual stresses along the depth of the hole $(2 \mathrm{~mm})$ drilled in titanium Grade 12. The resulting values correspond to negative values obtained by the sectioning method. However, they are lower by around 100-200 MPa from the ones that are provided using the sectioning method. This difference could be explained by a fact that residual stresses relaxed by extension $\Delta L$ (the sectioning method) represent averaged values over the length $L$. Values $\sigma_{x}^{r}(z)$ and $\sigma_{y}^{r}(z)$ are equal to zero at the ends of slices; thus, in the middle of slices the residual stress could approach the values obtained by the hole drilling method. We also have to note that the relatively low rotational speed applied for titanium alloys, i.e., $6000 \mathrm{rpm}$, could lead to the overestimation of residual stresses by around 19\% (Ref 40, 41).

The existence of compressive residual stresses in titanium Grade 12 layer cannot be explained by the simple model proposed in Ref 16, 22. In the present case, the layer of titanium Grade 12 is explosively welded to steel through interlayer made of titanium Grade 1. It is a very unusual combination of welded materials in which one titanium alloy hard deformable (elongation $A=20 \%$ - Ti Grade 12) must compose solid interface with another titanium alloy. The residual stresses could be a result of the phase transformation. For example, the martensite phase transformation from $\beta$ to $\alpha$ ' (hexagonal martensite) leads to increase in volume and, as a result, compressive residual stresses could be induced. However, titanium Grade 12 (Ti$0.3 \mathrm{Mo}-0.8 \mathrm{Ni}$ ) is classified to $\alpha$ or near- $\alpha$ alloy with a little amount of $\beta$ phase (Ref 42 ). The more the volume changes from a body-centered cubic crystal structure $(\beta)$ to hexagonal type $\left(\alpha^{\prime}\right)$ is not significant (Ref 43,44$)$ with the small production of residual stresses.

The previous model (Ref 16, 22) does not consider the effects taking place at high strain rates. According to Weertman (Ref 45), the total strain in a direction parallel to a shock wave front must be equal to zero. It results from the summation of tensile plastic strain and elastic hydrostatic compression strain. In the present case, the source of the shock wave is an impact of two titanium layers and the front of the wave is parallel to the created interface. Thus, the propagating shock wave creates hydrostatic compressive stresses in both titanium layers which are locked by the formed solid bond. The interior force equilibrium requires the generation of tensile residual stress in steel layer. In accordance with the presented model, the tensile residual stress could not be locked during shock wave, but this phenomenon is observed in some explosively welded materials (Ref 16, 22). We must note that Weertman (Ref 45) did not consider many effects associated with the source of shock wave such as local and rapid temperature rising/cooling, and different thermal and mechanical properties of welded materials. It is concluded that the process of residual stress formation during explosive welding depends on many factors such as mechanical and thermal properties of joined materials, dimensions of bonded layers and welding parameters. Thus, we can also forecast that the values of residual stress components are not equally distributed along the welded plate due to some variation in detonation velocity.

The observed adiabatic shear bands (ASB in Fig. 10) result from the very high compressive stresses generated during the impact of titanium Grade 12 layer with titanium Grade 1. During the impact of two titanium layers, compressive stress is induced and, consequently, the material from two layers is ejected in the parallel direction to the interface (from left to right in Fig. 9 and 10). The ejection of titanium Grade 1 creates some irregular bulges, and the ejection of titanium Grade 12 initiates adiabatic shear bands in the shape of a curve. When the adiabatic shear band is initiated, the compressive stress is partially relaxed, but due to the propagation of detonation wave the processes of material ejection and stress increasing start again until formation of another adiabatic shear band.

\section{Conclusions}

Based on the performed studies, the following conclusions are drawn:

- Biaxial compressive residual stress state is observed in titanium Grade 12 flyer layer and in titanium Grade 1 interlayer.

- Tensile residual stress occupies a band with a thickness of around $5 \mathrm{~mm}$ in steel layer in the vicinity of the interface.

- The tensile-compressive residual stress distribution along the depth of explosively welded plate is explained by the shock wave effect.

- Adiabatic shear bands are observed in titanium Grade 12 layer in the vicinity of interface with titanium Grade 1 interlayer. Such bands are initiated as a result of high compression and material ejection in the parallel direction to the created interface.

- The formation process of residual stresses during explosive welding is hard to predict without a prior detailed finite element analysis which must take into account many factors, such as welding parameters, physical properties of welded materials in function of strain rate and temperature, and dimensions of welded layers.

\section{Open Access}

This article is distributed under the terms of the Creative Commons Attribution 4.0 International License (http://creativecommons.org/ licenses/by/4.0/), which permits unrestricted use, distribution, and reproduction in any medium, provided you give appropriate credit to the original author(s) and the source, provide a link to the Creative Commons license, and indicate if changes were made.

\section{References}

1. J.N. DuPont, S. Babu, and S. Liu, Welding of Materials for Energy Applications, Metall. Mater. Trans. A, 2013, 44(7), p 3385-3410. https://doi.org/10.1007/s11661-013-1643-9

2. T.M. Ahn, B.S. Lee, and P. Soo, Identification of Crevice Corrosion in the Titanium Alloy TiCode-12 in Simulated Rock Salt Brine at $150^{\circ} \mathrm{C}$, No. BNL-NUREG-32107, 1982

3. S. Kaushal, D. Gupta, and H. Bhowmick, On Development and Wear Behavior of Microwave-Processed Functionally Graded Ni-SiC Clads on SS-304 Substrate, J. Mater. Eng. Perform., 2017, 27(2), p 1-10. https://doi.org/10.1007/s11665-017-3110-Z

4. Y. Sakai, K. Nakamura, and K. Shiokawa, Recent Technologies for Geothermal Steam Turbines, Fujii Electr. Rev., 2005, 51(3), p 90-95 
5. B. Crossland, Explosive Welding of Metals and its Application, Clarendon Press, Oxford, 1982

6. F. Findik, Recent Developments in Explosive Welding, Mater. Des., 2011, 32(3), p 1081-1093. https://doi.org/10.1016/j.matdes.2010.10. 017

7. H. Paul, M. Faryna, M. Prażmowski, and R. Bański, Changes in the Bonding Zone of Explosively Welded Sheets, Arch. Metall. Mater. 2011, 56(2), p 463-474. https://doi.org/10.2478/v10172-011-0050-8

8. H. Paul, J. Morgiel, T. Baudin, F. Brisset, M. Prażmowski, and M. Miszczyk, Characterization of Explosive Weld Joints by TEM and SEM/EBSD, Arch. Metall. Mater., 2014, 59(3), p 1129-1136. https:// doi.org/10.2478/amm-2014-0197

9. S. Yang and J. Bao, Microstructure and Properties of $5083 \mathrm{Al} / 1060 \mathrm{Al} /$ AZ31 Composite Plate Fabricated by Explosive Welding, J. Mater. Eng. Perform., 2018, https://doi.org/10.1007/s11665-018-3174-4

10. P. Chen, J. Feng, Q. Zhou, E. An, J. Li, Y. Yuan, and S. Ou, Investigation on the Explosive Welding of 1100 Aluminum Alloy and AZ31 Magnesium Alloy, J. Mater. Eng. Perform., 2016, 25(7), p 2635-2641

11. M. Fan, W. Yu, W. Wang, X.Z. Guo, K. Jin, R. Miao, W. Hou, N. Kim, and J. Tao, Microstructure and Mechanical Properties of ThinMultilayer Ti/Al Laminates Prepared by One-Step Explosive Bonding, J. Mater. Eng. Perform., 2017, 26(1), p 277-284

12. M. Wachowski, M. Gloc, T. Ślęzak, T. Płociński, and K.J. Kurzydłowski, The Effect of Heat Treatment on the Microstructure and Properties of Explosively Welded Titanium-Steel Plates, J. Mater. Eng. Perform., 2017, 26(3), p 945-954

13. D.M. Fronczek, R. Chulist, L. Litynska-Dobrzynska, S. Kac, N. Schell, Z. Kania, Z. Szulc, and J. Wojewoda-Budka, Microstructure and Kinetics of Intermetallic Phase Growth of Three-Layered A1050/ AZ31/A1050 Clads Prepared by Explosive Welding Combined with Subsequent Annealing, Mater. Des., 2017, 130, p 120-130. https://doi. org/10.1016/j.matdes.2017.05.051

14. X. Guo, Y. Ma, K. Jin, H. Wang, J. Tao, and M. Fan, Effect of StandOff Distance on the Microstructure and Mechanical Properties of Ni/ $\mathrm{Al} / \mathrm{Ni}$ Laminates Prepared by Explosive Bonding, J. Mater. Eng. Perform., 2017, 26(9), p 4235-4244

15. A. Karolczuk, M. Kowalski, R. Bański, and F. Żok, Fatigue Phenomena in Explosively Welded Steel-titanium Clad Components Subjected to Push-Pull Loading, Int. J. Fatigue, 2013, 48, p 101-108. https://doi.org/10.1016/j.ijfatigue.2012.10.007

16. A. Karolczuk, M. Kowalski, K. Kluger, and F. Żok, Identification of Residual Stress Phenomena Based on the Hole Drilling Method in Explosively Welded Steel-Titanium Composite, Arch. Metall. Mater. 2014, 59(3), p 1129-1133. https://doi.org/10.2478/amm-2014-0195

17. S.A. Al-Duheisat and A.S. El-Amoush, Effect of Deformation Conditions on the Corrosion Behavior of the Low Alloy Structural Steel Girders, Mater. Des., 2016, 89, p 342-347. https://doi.org/10. 1016/j.matdes.2015.09.160

18. L. Calabrese, E. Proverbio, G. Galtieri, and C. Borsellino, Effect of Corrosion Degradation on Failure Mechanisms of Aluminium/Steel Clinched Joints, Mater. Des., 2015, 87, p 473-481. https://doi.org/10. 1016/j.matdes.2015.08.053

19. R.M.N. Fleury and D. Nowell, Evaluating the Influence of Residual Stresses and Surface Damage on Fatigue Life of Nickel Superalloys, Int. J. Fatigue, 2017, 105, p 27-33. https://doi.org/10.1016/j.ijfatigue. 2017.08.015

20. L. Chen, D. Zeng, Z. Liu, S. Bai, and J. Li, Improving the Fatigue Crack Propagation Resistance and Damage Tolerance of 2524-T3 Alloy with Amorphous Electroless Ni-P Coating, J. Mater. Eng. Perform., 2018, 27(2), p 881-888. https://doi.org/10.1007/s11665-0183169-1

21. J.T. Bonarski, B. Kania, K. Bolanowski, and A. Karolczuk, Utility of Stress-Texture Characteristics of Structural Materials by X-Ray Technique, Arch. Metall. Mater, 2015, https://doi.org/10.1515/amm2015-0370

22. M. Sedighi and M. Honarpisheh, Experimental Study of ThroughDepth Residual Stress in Explosive Welded $\mathrm{Al}-\mathrm{Cu}-\mathrm{Al}$ Multilayer, Mater. Des., 2012, 37, p 577-581. https://doi.org/10.1016/j.matdes. 2011.10.022

23. A. Karolczuk, K. Kluger, M. Kowalski, F. Żok, and G. Robak, Residual Stresses in Steel-Titanium Composite Manufactured by Explosive Welding, Mater. Sci. Forum, 2012, 726, p 125-132. https://doi.org/10.4028/www.scientific.net/MSF.726.125
24. W. Yasheng, C. Hongneng, and M. Ninxu, Measurement of Residual Stresses in a Multi-Layer Explosive Welded Joint with Successive Milling Technique, Strain, 1999, 35(1), p 7-10

25. K. Saksl, Z. Szulc, M. Gloc, O. Milkovič, J. Ďurišin, Ł. Ciupiński, A. Arnbjörnsson, D. Ostroushko, E. Mazancová, and F. Bertram, Evaluation of Residual Strains and Stresses Using Two-Dimensional X-Ray Difraction, in METAL 2016 - 25th Anniversary International Conference on Metallurgy and Materials, Conference Proceedings, 2016

26. Y.V. Taran, A.M. Balagurov, B.M. Sabirov, A. Evans, V. Davydov, and A.M. Venter, Residual Stresses in a Stainless Steel-Titanium Alloy Joint Made with the Explosive Technique, J. Phys. Conf. Ser., 2012, 340

27. R. Thomas, Titanium in the Geothermal Industry, Geothermics, 2003, 32(4), p 679-687

28. T.M. Ahn and P. Soo, Container Assessment-Corrosion Study of HLW Container Materials, (The Nuclear Waste Management Division, Department of nuclear energy, Brookhaven National Laboratory Upton, New York 11973), 1982

29. G.S. Schajer, Ed., Practical Residual Stress Measurement Methods, Wiley, West Sussex, 2013

30. N. Tebedge, G. Alpsten, and L. Tall, Residual-Stress Measurement by the Sectioning Method, Exp. Mech., 1973, 13(2), p 88-96. https://doi. org/10.1007/BF02322389

31. ASTM E837 - 13a, Standard Test Method for Determining Residual Stresses by the Hole-Drilling Strain-Gage Method, ASTM Int. West Conshohocken, PA, 2013

32. N.S. Rossini, M. Dassisti, K.Y. Benyounis, and A.G. Olabi, Methods of Measuring Residual Stresses in Components, Mater. Des., 2012, 35, p 572-588. https://doi.org/10.1016/j.matdes.2011.08.022

33. Y. Yang, Z. Xinming, L. Zhenghua, and L. Qingyun, Adiabatic Shear Band on the Titanium Side in the Ti/Mild Steel Explosive Cladding Interface, Acta Mater, 1996, 44(2), p 561-565

34. M.X. Xie, L.J. Zhang, G.F. Zhang, J.X. Zhang, Z.Y. Bi, and P.C. Li, Microstructure and Mechanical Properties of CP-Ti/X65 Bimetallic Sheets Fabricated by Explosive Welding and Hot Rolling, Mater. Des., 2015, 87, p 181-197. https://doi.org/10.1016/j.matdes.2015.08. 021

35. A. Loureiro, R. Mendes, J.B. Ribeiro, R.M. Leal, and I. Galvão, Effect of Explosive Mixture on Quality of Explosive Welds of Copper to Aluminium, Mater. Des., 2016, 95, p 256-267. https://doi.org/10.1016/ j.matdes.2016.01.116

36. M. Gloc, M. Wachowski, T. Plocinski, and K.J. Kurzydlowski, Microstructural and Microanalysis Investigations of Bond Titanium Grade1/Low Alloy Steel St52-3 N Obtained by Explosive Welding, $J$. Alloys Compd., 2016, 671, p 446-451. https://doi.org/10.1016/j. jallcom.2016.02.120

37. J. Liu, Q. Fan, H. Cai, and F. Wang, Underlying Mechanism of Periodical Adiabatic Shear Bands Generated in Ti-6Al-4 V Target by Projectile Impact, Mater. Des., 2015, 87, p 231-237. https://doi.org/10. 1016/j.matdes.2015.08.034

38. B.F. Wang and Y. Yang, Microstructure Evolution in Adiabatic Shear Band in Fine-Grain-Sized Ti-3Al-5Mo-4.5 V Alloy, Mater. Sci. Eng., A, 2008, 473(1-2), p 306-311

39. P. Sengupta, G. Sharma, and G.K. Dey, Interfacial Reactions Between Ti Grade 12 Titanium Alloy and Stainless (SS-304), $J$. Nucl. Mater, 2015, 457, p 205-208. https://doi.org/10.1016/j. jnucmat.2014.11.011

40. C. Barile, C. Casavola, G. Pappalettera, and C. Pappalettere, Analysis of the Effects of Process Parameters in Residual Stress Measurements on Titanium Plates by HDM / ESPI, Measurement, 2014, 48, p 220227. https://doi.org/10.1016/j.measurement.2013.11.014

41. D. Upshaw, M. Steinzig, and J. Rasty, Influence of Drilling Parameters on the Accuracy of Hole-Drilling Residual Stress Measurements, in Engineering Applications of Residual Stress, Volume 8: Proceedings of the 2011 Annual Conference on Experimental and Applied Mechanics, T. Proulx, Ed., (New York, NY), Springer, New York, 2011, p 95-109. https://doi.org/10.1007/978-1-4614-0225-1_12

42. G. Welsch, R. Boyer, and E.W. Collings, Materials Properties Handbook: Titanium Alloys, ASM International, Materials Park, 1993

43. J. Ahn, E. He, L. Chen, R.C. Wimpory, J.P. Dear, and C.M. Davies, Prediction and Measurement of Residual Stresses and Distortions in Fibre Laser Welded Ti-6Al-4 V Considering Phase Transformation, Mater. Des., 2017, 115, p 441-457. https://doi.org/10.1016/j.matdes. 2016.11.078 
44. W. Szkliniarz and G. Smołka, Analysis of Volume Effects of Phase Transformation in Titanium Alloys, J. Mater. Process. Technol., 1995, 53(1-2), p 413-422. https://doi.org/10.1016/0924-0136(95)01998-T
45. J. Weertman, Moving Dislocations in a Shock Front, Shock Waves and High-Strain-Rate Phenomena in Metals, M.A. Meyers and L.E. Murr, Eds., (New York), 1981, p 469-486 